\title{
Invasive Coronary Physiological Assessment in Symptomatic Middle-Aged Endurance Athletes
}

\author{
Omar M. Issa, ${ }^{(1)}$ J. Sawalla Guseh, ${ }^{(1)}$ Ignacio Inglessis, ${ }^{(\mathbb{C})}$ Aaron L. Baggish ${ }^{(1)}$ \\ Massachusetts General Hospital, Boston, MA - EUA
}

\begin{abstract}
Despite the health benefits of routine exercise, coronary artery disease (CAD) is common among older competitive athletes and is an important cause of sudden cardiac death. Athletes with suspected or confirmed CAD routinely undergo conventional coronary angiography involving the performance of invasive coronary physiological assessment using the fractional flow reserve (FFR) or the instantaneous-wave free ratio (iFR). Data defining the role of invasive coronary physiological assessment, while robust in general clinical populations, are untested among older competitive athletes with CAD. The paper discusses the challenges and uncertainties surrounding the use of the FFR and iFR in this unique population with an emphasis on the need for future work to better define this approach.
\end{abstract}

\section{Introduction}

Although routine vigorous exercise promotes favorable changes in atherosclerotic vascular risk factors, it cannot provide complete immunity from coronary artery disease (CAD), regardless of its level. CAD is common among older competitive athletes, ${ }^{1}$ and is an important cause of sudden cardiac death. ${ }^{2,3}$ Effective clinical management of athletes with $\mathrm{CAD}$, much like non-athletic patients, requires a strategy that integrates lifestyle modification, pharmacotherapy, and coronary revascularization. Most athletes with $\mathrm{CAD}$, with diagnosis made by symptoms,

\section{Keywords}

Athletes; Adult; Circuit Based Exercise/mortality; Physical Fitness; Coronary Artery Disease; Fractional Flow Reserve; Myocardial; Coronary Angiography/methods. abnormal findings during functional testing, or through the increasing use of computed tomography screening will undergo conventional coronary angiography. This method facilitates a definitive determination of coronary anatomy and provides an opportunity for simultaneous percutaneous revascularization.

The decision to perform percutaneous coronary revascularization in competitive athletes depends on medical therapy options and coronary lesion severity. For determination of coronary lesion severity, visual inspection of coronary anatomy has been increasingly associated with invasive coronary physiology analysis, which has emerged as a powerful tool to guide coronary revascularization decisions. Measurement of the fractional flow reserve (FFR), and more recently, the instantaneous-wave free ratio (iFR) to assess the functional significance of angiographically intermediate coronary stenoses have been shown to improve clinical outcomes, ${ }^{4-7}$ and has been established as the standard of care for the general population. ${ }^{8}$ However, competitive athletes represent a population with unique physiology where these modalities have not been well validated. Thus, application of data derived from non-athletic populations has the potential to lead clinicians astray. This paper examines $\neg$ the use of invasive coronary physiological assessment among athletes with coronary disease, with an emphasis on potential limitations that arise from the absence of physiologic and outcome data derived from this specific population.

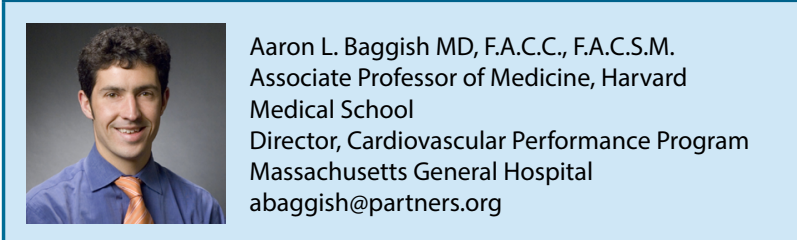




\section{Clinical case study}

A 49-year-old male marathon runner with many years with consistent sub-three hour finish times presents with progressive exertional dyspnea and consequent reductions in his running pace over a 6-month period. He also noted a significant increase in race time in the last marathon three months ago. The atherosclerotic risk factor profile was marked by the presence of dyslipidemia, treated with low-dose statin, and a family history of premature CAD (his father and uncle). He underwent a maximal symptom-limited exercise test with metabolic gas exchange on the treadmill that demonstrated a functional capacity well above the predicted peak value for age $/$ sex $\left(\mathrm{VO}_{2 \text { peak }}=53.0 \mathrm{ml} / \mathrm{kg}\right.$. min $)$ but experienced the described symptoms. In conjunction with dyspnea, there were 1 to 2-mm horizontal ST-segment depressions across the precordial leads of the exercise ECG, that emerged near peak exercise and resolved completely by 3 minutes of recovery. Transthoracic echocardiography demonstrated mild 4-chamber dilatation, preserved systolic and diastolic left ventricular function, and no significant valvular disease.

He underwent a conventional coronary angiography, which revealed a focal $60-70 \%$ stenosis by visual assessment in the proximal left anterior descending artery. The lesion was further characterized by FFR, which yielded a value of 0.82 . Based on data from the FAME trials, ${ }^{4,5}$ from which an FFR revascularization cutpoint of 0.80 was established, intervention was deferred. Despite presenting with angina syndrome and objective evidence of ischemia on functional testing, the patient was advised that his CAD was not "severe enough" to justify an intervention and then clinical treatment with beta-blocker, long-acting nitrate preparation, statin, and aspirin was initiated. As often observed in athletic patients, significant undesirable side effects were caused by the beta-blocker (further reduction in exercise capacity with no improvement of angina), nitrate (post-exertional orthostatic intolerance), and statin (myalgia), leading to treatment noncompliance and discontinuation. He presented again eight months later after being successfully resuscitated from cardiac arrest that occurred 100 meters before the finish line of a large city marathon. Repeat coronary angiography showed no evidence of plaque rupture or new lesions, and stable left anterior descending coronary artery disease both by visual angiography and repeat FFR. After a discussion with the patient about management options, the proximal left anterior descending artery was treated with a drug eluting stent.

\section{Discussion}

This case study highlights several areas of clinical uncertainty regarding the use of invasive coronary flow assessment in competitive athletes with atherosclerotic coronary disease. The central uncertainty relates to whether the guideline-supported decision to forgo revascularization based on the FFR data initially obtained from the patient was the appropriate management option. This question cannot be answered by the available clinical trial data and underscores the challenges of applying invasive coronary physiological assessment in patients who were unrepresented in the literature. Clinical cases such as this illustrate the need for future investigations designed to assess the utility of FFR and iFR in athletes.

FFR is a ratio that quantifies the difference between the proximal and distal blood pressure surrounding a focal coronary stenosis during adenosine-induced hyperemia and provides a quantitative assessment of stenosis severity. ${ }^{9}$ For example, an FFR of 0.82 obtained across a focal stenosis of the left anterior descending artery indicates an $18 \%$ reduction in blood flow distal to the stenosis under pharmacologically-induced maximal hyperemia. Although the catheter actually measures coronary pressure, the hyperemic conditions are thought to eliminate the effect of the resistance vessels such that the coronary pressure is essentially equivalent to coronary blood flow. ${ }^{9}$ The iFR is an increasingly popular alternative as it obviates the need for adenosine-induced hyperemia by assessing the flow gradient during a quiescent period in diastole, when microvasculature resistance is stable, which allows uniform measurements during the resting state. ${ }^{10}$ Accordingly, FFR and iFR provide insight into the supply component of the myocardial ischemia supply/demand relationship.

Measurement of FFR or iFR is typically performed when the severity of angiographic lesion cannot be visually determined and the decision to proceed with or to defer revascularization must be made. The use of FFR/iFR in this context relies on clinical cut-points or binary "lines in the sand" which differentiate adequate versus inadequate blood supply. Current recommendations for FFR/iFR cut-points have emerged from careful analysis of clinical trial and registry data, ${ }^{4-7}$ with emphasis on hard outcomes including mortality and the need for future revascularization. Specifically, FFR and iFR cut-points have been chosen to represent a lesion severity at which the risk-benefit balance of percutaneous intervention favored intervention rather 
than conservative management among populations enrolled in these trials. In the case of the pivotal Fractional Flow Reserve Versus Angiography for MultiVessel Evaluation (FAME) 1 and FAME 2 trials, $^{4,5}$ the study cohorts were predominantly older (median age of about 65 years old) and male and, in the former, all patients had multi-vessel CAD with at least two lesions with $>50 \%$ luminal narrowing (Table 1 ). Both studies demonstrated an improvement in the incidence of major adverse cardiovascular events when using a FFR-guided strategy in stable CAD, FAME 2 being halted prematurely due to the robust early benefit. ${ }^{4,5}$ The key iFR studies, the Functional Lesion Assessment of Intermediate Stenosis to Guide Revascularization (DEFINE-FLAIR) and Instantaneous Wave-free Ratio versus Fractional Flow Reserve in Patients with Stable Angina Pectoris or Acute Coronary Syndrome (iFR-SWEDEHEART) trials, were comprised of similar population demographics (Table 1). Both studies demonstrated a non-inferiority of iFR compared to the gold standard FFR with respect to major cardiovascular outcomes..$^{6,7}$ As is often the case in clinical sports cardiology, it is prudent to consider whether care patterns that have emerged from these clinical trials are universally appropriate for use among competitive athletes.

An important assumption when applying FFR (and iFR) cut-points is that they reflect the ischemic threshold of the population studied, below which coronary supply is insufficient to meet myocardial demands. It is noteworthy that endurance athletes have a unique supply/demand relationship whereby they regularly endure sustained increases in heart rate, blood pressure, and cardiovascular workload during training and competition. In doing so, they far exceed the peak myocardial oxygen demands of the typical study patients that have been enrolled in the FFR/iFR cut-point derivation trials. When considering the high myocardial oxygen consumption and associated neuro-hormonal activation that is present at times of peak performance, it is likely that endurance athletes with focal CAD will experience significant myocardial demand ischemia despite FFR (and iFR) values that lie above the traditional cut-points.

Table 1 - A summary of the pivotal trials of invasive hemodynamic assessment

\begin{tabular}{|c|c|c|c|c|}
\hline Clinical trial & (n) & Age & $\%$ Male & Inclusion / coronary anatomy \\
\hline $\begin{array}{l}\text { FAME } 1 \\
(2009)\end{array}$ & 1005 & $\begin{array}{c}64.2+/-10.2 \text { years } \\
\text { (Angiography group) } \\
64.6+/-10.3 \text { years (FFR } \\
\text { group) }\end{array}$ & $74.0 \%$ & $\begin{array}{c}\text { Patients with indications for PCI } \\
\text { who had stenosis }>50 \% \text { in at least } \\
2 \text { of } 3 \text { major coronary vessels } \\
{ }^{*} 67.4 \% \text { had stable angina }\end{array}$ \\
\hline $\begin{array}{l}\text { FAME } 2 \\
(2018)\end{array}$ & 888 & $\begin{array}{c}63.5+/-9.4 \text { years } \\
(\text { PCI group) } \\
63.9+/-9.6 \text { years } \\
\text { (Medical therapy group) }\end{array}$ & $78.2 \%$ & $\begin{array}{l}\text { Patients with stable angina in } \\
\text { whom PCI was being considered } \\
\text { with at least one functionally } \\
\text { significant stenosis as determined } \\
\text { by FFR } \leq 0.80\end{array}$ \\
\hline $\begin{array}{l}\text { DEFINE-FLAIR } \\
(2017)\end{array}$ & 2492 & $\begin{array}{l}65.5+/-10.8 \text { years } \\
\quad \text { (iFR group) } \\
65.2+/-10.6 \text { years } \\
\quad \text { (FFR group) }\end{array}$ & $75.9 \%$ & $\begin{array}{c}\text { Patients with stable angina or } \\
\text { ACS who had an indication for } \\
\text { physiologically guided assessment } \\
\text { of a coronary lesion ( } 40 \text { to } 70 \% \\
\text { stenosis on visual assessment) } \\
{ }^{*} 80.2 \% \text { had stable angina }\end{array}$ \\
\hline $\begin{array}{l}\text { iFR-SWEDEHEART } \\
\text { (2017) }\end{array}$ & 2037 & $\begin{array}{l}67.6+/-9.6 \text { years } \\
\quad \text { (iFR group) } \\
67.4+/-9.2 \text { years } \\
\quad \text { (FFR group) }\end{array}$ & $74.7 \%$ & $\begin{array}{c}\text { Patients with stable angina or } \\
\text { ACS who had an indication for } \\
\text { physiologically guided assessment } \\
\text { of a coronary lesion ( } 40 \text { to } 80 \% \\
\text { stenosis on visual assessment) } \\
{ }^{*} 62.1 \% \text { had stable angina }\end{array}$ \\
\hline
\end{tabular}


Demand ischemia during endurance exercise is not trivial and was identified to be the leading cause of cardiac arrest during exercise among aging marathon runners in the Race Associated Cardiac Arrest Registry (RACER). ${ }^{3}$ It is also noteworthy that in this study, the highest proportion of these sudden cardiac deaths occurred in the final stretches of the marathon when runners typically engage in a "finish-line surge", suggesting that an intensity-dependent phenomenon may be precipitating malignant ventricular arrhythmia and subsequent cardiac arrest. Overall, these observations suggest that the risk of a "stable CAD" may not be the same in endurance athletes as in their less active counterparts. This may be most pronounced in triathlon participants, described to have a 2-to-3 fold increase in these events. ${ }^{11}$ This elevated cardiovascular risk, when coupled with the general unwillingness of these competitors to take antiischemic medications, has the potential to alter the risk/ benefit balance for intervention over medical therapy (or vice versa) for a given FFR or iFR “cut point."

Thus, with stakes this high and indecision regarding the precise role of invasive coronary physiological assessment in competitive athletes, clinicians should be cautious in their interpretation of borderline values. It is within this "grey zone" that measurement uncertainty increases dramatically, ${ }^{12}$ and thus acting hastily on one indeterminate data point may be ill-advised..$^{12}$ For this reason, functional data from carefully conducted maximal effort, exercise stress test should be obtained before coronary angiography whenever possible and should be considered during the revascularization decision-making process. Among competitive athletes with documented evidence of ischemia during prior functional testing, revascularization of seemingly indeterminate lesions may be a preferred option over medical therapy as suggested by a recent European consensus statement (Class IIa). ${ }^{13}$ At the present time, ACC/AHA task force guidelines do not provide a definitive recommendation regarding revascularization, but endorse restricting athletes with stable CAD and inducible ischemia to sports with low dynamic and low to moderate static demands (Class $\mathrm{IIb})$. Thus, the decision boils down to restriction from all endurance sports or "elective" revascularization with a goal of eliminating demand ischemia. ${ }^{14}$ Despite this difference between European and American recommendations, writing committees from both regions identify inducible ischemia as a high-risk feature among competitive endurance athletes.

Ultimately, more scientific investigation is needed to identify accurate FFR and iFR cut-points which reflect the true risk/benefit balance of percutaneous revascularization in competitive athletes with CAD. While we await further data, it is prudent to engage the athletic patient in a shared-decision making discussion about medical therapy versus revascularization prior to catheterization as both strategies have distinct pros and cons. This approach enables sports cardiologists and their patients to enter into a clinical decisionmaking partnership. ${ }^{15,16}$ Such sharing of clinical decision making optimally positions the clinician to make revascularization decisions with the patient-athlete, by integrating clinical history, ancillary testing, and individualized goals of care.

\section{Author contributions}

Conception and design of the research: Issa OM, Baggish AL. Acquisition of data: Issa OM, Baggish AL. Writing of the manuscript: Issa OM, Guseh JS, Inglessis I, Baggish AL. Critical revision of the manuscript for intellectual content: Issa OM, Guseh JS, Inglessis I, Baggish AL.

\section{Potential Conflict of Interest}

No potential conflict of interest relevant to this article was reported.

\section{Sources of Funding}

There were no external funding sources for this study.

\section{Study Association}

This study is not associated with any thesis or dissertation work.

\section{Ethics approval and consent to participate}

This article does not contain any studies with human participants or animals performed by any of the authors. 


\section{References}

1. Morrison BN, McKinney J, Isserow S, Lithwick D, Taunton J, Nazzari H, et al. Assessment of cardiovascular risk and preparticipation screening protocols in masters athletes: the Masters Athlete Screening Study (MASS): a cross-sectional study. BMJ Sport Exerc Med. 2018;4(1):e000370.

2. Mittleman MA, Maclure M, Tofler GH, Sherwood JB, Goldberg RJ, Muller JE. Triggering of acute myocardial infarction by heavy physical exertion. Protection against triggering by regular exertion. Determinants of Myocardial Infarction Onset Study Investigators. N Engl J Med. 1993;329(23):1677-83.

3. Kim JH, Malhotra R, Chiampas G, d'Hemecourt P, Troyanos C, Cianca $\mathrm{J}$, et al. Cardiac arrest during long-distance running races. N Engl J Med. 2012;366(1):130-40.

4. Tonino PA, De Bruyne B, Pijls NH, Siebert U, Ikeno F, van' t Veer M, et al. Fractional flow reserve versus angiography for guiding percutaneous coronary intervention. N Engl J Med. 2009;360(3):213-24.

5. De Bruyne B, Fearon WF, Pijls NH, Barbato E, Tonino P, Piroth Z, et al. Fractional Flow Reserve-Guided PCI for Stable Coronary Artery Disease. N Engl J Med. 2014;371(13):1208-17.

6. Davies JE, Sen S, Dehbi HM, Al-Lamee R, Petraco R, Nijjer SS, et al. Use of the Instantaneous Wave-free Ratio or Fractional Flow Reserve in PCI. N Engl J Med. 2017;376(19):1824-34.

7. Götberg M, Christiansen EH, Gudmundsdottir IJ, Sandhall L, Danielewicz M, Jakobsen L, et al. Instantaneous Wave-free Ratio versus Fractional Flow Reserve to Guide PCI. N Engl J Med. 2017;376(19):181323.

8. Levine GN, Bates ER, Blankenship JC, Bailey SR, Bittl JA, Cercek B, et al. $2011 \mathrm{ACCF} / \mathrm{AHA} / \mathrm{SCAI}$ guideline for percutaneous coronary intervention. J Am Coll Cardiol. 2011;58(24):e44-122.

9. Pijls NH, van Son JA, Kirkeeide RL, De Bruyne B, Gould KL. Experimental basis of determining maximum coronary, myocardial, and collateral blood flow by pressure measurements for assessing functional stenosis severity before and after percutaneous transluminal coronary angioplasty. Circulation. 1993;87(4):1354-67.
10. Sen S, Escaned J, Malik IS, Mikhail GW, Foale RA, Mila R, et al. Development and validation of a new adenosine-independent index of stenosis severity from coronary wave-intensity analysis: results of the ADVISE (ADenosine Vasodilator Independent Stenosis Evaluation) study. J Am Coll Cardiol. 2012;59(15):1392-402.

11. Harris KM, Creswell LL, Haas TS, Thomas T, Tung M, Isaacson E, et al. Death and Cardiac Arrest in U.S. Triathlon Participants, 1985 to 2016: A Case Series. Ann Intern Med. 2017;167(8):529-35.

12. Petraco R, Sen S, Nijjer S, Echavarria-Pinto M, Escaned J, Francis DP, et al. Fractional flow reserve-guided revascularization: Practical implications of a diagnostic gray zone and measurement variability on clinical decisions. JACC Cardiovasc Interv. 2013;6(3):222-5.

13. Borjesson M, Dellborg M, Niebauer J, LaGerche A, Schmied C, Solberg EE, et al. Recommendations for participation in leisure time or competitive sports in athletes-patients with coronary artery disease: a position statement from the Sports Cardiology Section of the European Association of Preventive Cardiology (EAPC). Eur Heart J. 2019;40(1):13-8

14. Thompson PD, Myerburg RJ, Levine BD, Udelson JE, Kovacs RJ, American Heart Association Electrocardiography and Arrhythmias Committee of Council on Clinical Cardiology, Council on Cardiovascular Disease in Young, Council on Cardiovascular and Stroke Nursing, Council on Functional Genomics and Translational Biology and AC of C. Eligibility and Disqualification Recommendations for Competitive Athletes with Cardiovascular Abnormalities: Task Force 8: Coronary Artery Disease: A Scientific Statement from the American Heart Association and American College of Cardiology. Circulation. 2015;132(22):e310-4.

15. Baggish AL, Ackerman MJ, Putukian M, Lampert R. Shared Decision Making for Athletes with Cardiovascular Disease: Practical Considerations. Curr Sports Med Rep. 2019;18(3):76-81.

16. Baggish AL, Ackerman MJ, Lampert R. Response by Baggish et al to Letter Regarding Article, "Competitive Sport Participation Among Athletes With Heart Disease: A Call for a Paradigm Shift in Decision Making". Circulation. 2018;137(18):1988-9. 